\title{
A CONTRIBUIÇÃO DA UNIVERSIDADE NA FORMAÇÃO DE SUJEITOS SOCIALMENTE RESPONSÁVEIS: A disciplina de Ação Comunitária do curso de Comunicação Social do CEULP/ULBRA
}

\author{
SUZI AMÉRICO NOGUEIRA DA SILVA, \\ ANA LEONOR MORAIS SANTOS
}

\begin{abstract}
RESUMO - O presente artigo apresenta resultados de uma pesquisa que teve como objeto a disciplina acadêmica de Ação Comunitária, integrante da grade curricular do curso de Comunicação Social, com habilitação em Publicidade e Propaganda, do Centro Universitário Luterano de Palmas, Tocantins, Brasil. O projeto lança um olhar para a influência da formação do caráter social responsável dos profissionais da área da comunicação que cursaram esta disciplina na academia. Através de abordagem Quanti-Qualitativa foram aplicadas entrevistas semiestruturadas aos egressos do Curso de Comunicação Social do CEULP ULBRA. Foi entrevistada também a Professora da disciplina, $\operatorname{Dr}^{\mathrm{a}}$ Valdirene Cássia da Silva. Com a utilização dessas ferramentas metodológicas foi possível levantar dados onde se pôde observar o modo de trabalho dos egressos, e assim refletir quais ações executadas pelos alunos, agora profissionais, foram direta ou indiretamente influenciadas pelas vivências adquiridas durante os estudos feitos nas atividades propostas pela disciplina.
\end{abstract}

PALAVRAS-CHAVE - Comunicação; Ação; Cidadania; Comunidade; Responsabilidade Social.

\section{INTRODUÇÃO}

Ao longo de sua trajetória de formação acadêmica, profissionais da área de comunicação, residentes na cidade de Palmas, capital do Estado do Tocantins, cursaram a disciplina de Ação Comunitária, ofertada na grade curricular do curso de Comunicação Social com habilitação em Publicidade e Propaganda, tendo como eixo central a construção das noções de responsabilidade social através do uso de ferramentas aplicadas na comunicação.

O curso de Comunicação Social com habilitação em $\mathrm{Pu}$ blicidade e Propaganda foi implantado na Universidade Luterana de Palmas no ano de 1999. A disciplina de Ação Comunitária foi inserida na grade curricular do curso no ano de 2008 com o propósito de formar comunicólogos habilitados e capacitados para exercer atividades profissionais em diversas áreas da comunicação, atuando no mercado de trabalho com uma postura criativa, responsável, ética e reflexiva, aplicando criticamente o raciocínio lógico e científico, capazes de identificarem e solucionarem problemas pertinentes ao seu meio profissional, estando estes capacitados para a elaboração, o planejamento e a execução de um projeto de comunicação que pudesse oferecer à comunidade uma ação socialmente responsável.

Desde que a disciplina foi implantada, 181 alunos, hoje formados, desenvolveram projetos de cunho social para di- ferentes entidades e causas. Como parte fundamental da formação de um indivíduo consciente e responsável de seu lugar de fala em sua comunidade, ou no meio profissional em que convive, a universidade tem o papel de fomentar, através de seus cursos e disciplinas, conteúdos que possam agregar aos profissionais de diversas áreas de atuação características sociais que os diferenciem dos demais, promovendo de forma efetiva a formação de sujeitos sociais comprometidos com a sociedade e empenhados em desenvolver trabalhos voltados para o fortalecimento da cidadania.

O objetivo desse trabalho foi conhecer a disciplina de Ação Comunitária do Curso de Comunicação Social do CEULP ULBRA, analisar os resultados das ações realizadas e avaliar a eficácia da disciplina na formação de sujeitos socialmente responsáveis. Com base na revisão da literatura, na nossa própria observação e através de uma análise Quanti-Qualitativa foi possível traçar um estudo que pudesse apontar as influências das atividades executadas no curso da disciplina, nas atividades desenvolvidas posteriormente por alguns profissionais da comunicação, apontando alguns aspectos que destaquem em suas atividades ações voltadas para temas em responsabilidade social e principalmente em projetos que mostrem de forma acentuada as características desses profissionais no mercado de trabalho, enquanto sujeitos sociais preocupados em desenvolver ações para as empresas em que 
trabalham imprimindo o viés social comunitário em alguma ação que beneficie não apenas a entidade que representam, mas que possam beneficiar a comunidade, ou algum grupo social específico de sua cidade.

\section{A. CONCEPCÃ̃ DE CURRÍCULO}

Considerada como um espaço de saber, a universidade tem como grande desafio desenvolver uma grade curricular de maneira que a sua estrutura seja capaz de formar profissionais com a capacidade, competência e a habilidade de atuarem no mundo, aplicando as práticas e as teorias aprendidas no espaço acadêmico, levando este aprendizado para as suas relações interpessoais, atendendo de forma coerente e sem utopias. Moreira defende que para se organizar um currículo articulado nas instituições é preciso que ele seja usual e fácil de aplicar.

É necessário que haja a participação do educador na construção do currículo, como agente responsável nas ferramentas que serão utilizadas para o desenvolvimento do trabalho educacional que atenda às necessidades dos alunos, através de atividades que coloquem em evidência a valorização da tomada de decisões de forma crítica e coerente.

Para que se possa construir um currículo participativo que contemple todos os personagens envolvidos no processo de ensino, seja o corpo docente, ou o corpo acadêmico, é preciso elaborar um planejamento teórico-prático que busque aperfeiçoar as noções de participação, cidadania e democracia no contexto escolar pedagógico.

A partir daí, a organização e execução do currículo será direcionada para atender as necessidades dos tempos contemporâneos, provocando nos alunos a necessidade de desenvolvimento de sua autonomia, tornando-os cidadãos participativos, interativos com a sua comunidade, integrados de forma crítica no ambiente social ao qual pertencem, e acima de tudo cooperativos e dispostos a colocarem em prática a sua visão de um mundo melhor que contemple cada integrante social, propiciando aos mesmos viver em condições dignas. Neste prisma, a construção do currículo deve visar a possibilidade de promoção de uma integração curricular que promova o conhecimento tendo como base a realidade social dos seus alunos, fazendo com que eles possam refletir sobre as suas experiências de vida, sentindo-se contemplados dentro desse processo democrático de educação.

\section{B. O PAPEL SOCIAL DA UNIVERSIDADE}

Segundo Buarque [3], se fosse realizada uma pesquisa com o objetivo de identificar a função principal da universidade, uma grande parte dos questionados diria que era a formação de pessoal de nível superior.

Baseadas na ideia de que a Instituição Universitária tem um papel indispensável de responsabilidade para com as questões sociais, muitas universidades buscam aliar as funções de ensino, pesquisa e extensão com o papel de comprometimento para com os problemas da sociedade, voltando-se para $\mathrm{o}$ atendimento das demandas sociais mais urgentes.
De acordo com Melo e Novo [6], a formação do estudante não deve se limitar aos ensinamentos de sala de aula, e isso abre caminhos para ampliar o entendimento de currículo e, dessa forma, efetivar o real sentido de sua existência e importância na construção e geração de conhecimentos, que vão ao encontro das reais necessidades da população.

\section{A CONSTITUIÇÃO DO SUJEITO SOCIAL}

A noção de sujeito social é normalmente tomada com um sentido em si mesma, sem a preocupação de defini-la, outras vezes é tomada como sinônimo de indivíduo. Para essa análise usamos a definição de Charlot [4]: para o autor sujeito é um ser humano que possui uma historicidade; tem desejos e é movido por eles além de estar em relação com outros seres humanos que também são sujeitos.

O Sujeito é um ser social, com uma determinada origem familiar, que ocupa um determinado lugar social e se encontra inserido em relações sociais. Pode-se concluir então que o sujeito é um ser singular, que tem uma história, que interpreta o mundo e dá-lhe sentido, assim como dá sentido à posição que ocupa nele, às suas relações com os outros, à sua própria história e à sua singularidade.

A fim de compreendermos o protagonismo do estudante dentro de uma instituição universitária como um agente social propriamente dito, é necessário que façamos um mergulho teórico para entendermos anteriormente como se dá a construção desse protagonismo.

Para tanto devemos lançar um olhar inicial para o agente social tendo em vista o processo de construção do mesmo enquanto sujeito social. Para isso faremos um recorte seguindo a linha de que um dos meios utilizados para a formação do sujeito social é a educação. Neste recorte destacamos que durante o ensino superior o estudante pode potencializar a consciência social que construiu ao longo da sua trajetória de vida, tendo em vista que mesmo sabendo que a educação de um sujeito se faz na vida, é na aprendizagem, portanto que pode ocorrer a emancipação de sua consciência social, fazendo com que o sujeito passe a transferir para as suas ações cotidianas tudo o que aprendeu em seus processos educacionais.

Segundo Paulo Freire [12], é através da educação que o sujeito aprende o modo como se relaciona com o mundo a sua volta, desenvolvendo os vínculos criativos com a sua realidade interior e exterior, com as pessoas a sua volta, transformando tudo o que está a sua volta. Através desse processo de aprendizagem, o sujeito passa a construir a sua identidade pessoal que posteriormente irá refletir em sua condição como um agente social consciente de sua condição de integrante de uma comunidade, assumindo as suas responsabilidades diante da sociedade.

\section{O PAPEL DA COMUNICAÇÃO NA ESFERA SOCIAL}

A sociedade atual vive um momento de grandes mudanças, as inovações e as novas tecnologias estão causando verdadeiras transformações em todas as áreas do conhecimento e no que se refere a gerar novos saberes para a Humanidade. 
Em contraponto surgem também novos problemas no cenário social. Na tentativa de amenizar esses problemas, iniciativas privadas e associações variadas se empenham e se envolvem na tentativa de diminuir ou sanar os problemas do homem e do ambiente onde vive.

Dessa forma houve uma crescente nos movimentos sociais, e com isso difundiu-se os novos questionamentos quanto a importância da Comunicação na permanência e solidificação desses movimentos. Henriques [5] na introdução de seu livro Comunicação e estratégias de mobilização social nos diz que os media entraram para fazer parte desse cenário das reivindicações sociais, e com as múltiplas e novas possibilidades de transmissão de informações estão transformando a maneira como esses movimentos se apresentam, assim como os profissionais da Comunicação estão assumindo uma nova postura frente ao desenvolvimento comunitário.

\section{E. O PLANEJAMENTO DE COMUNICAÇÃO PARA A MOBILIZAÇÃO SOCIAL}

O conceito de comunicação sempre esteve associado ao de informação, contudo sabe-se que existe entre esses conceitos várias distinções. Segundo Araújo e Cardoso [2], percebe-se comunicação como "procedimentos pelos quais a informação pode ser tratada e transformada em saberes pelas pessoas e instituições". Sobre o conceito de Mobilização, Bernardo Toro e Nísia Werneck [9], em Mobilização Social - Um modo de construir a democracia e a participação [5], definem mobilizar como "convocar vontades para atuar na busca de um propósito comum, sob uma interpretação e um sentido também compartilhados" [9].

Considerando os dois conceitos apresentados acima, verifica-se que o sucesso de um projeto de Mobilização Social está diretamente ligado com a eficiência de um planejamento estratégico de comunicação.

O trabalho da Comunicação em um projeto de mobilização social deve nortear-se pela ideia de criar vínculos entre as pessoas que estejam dispostas a aderir à(s) causa(s) em questão. Para isso é necessário criar entre os atores envolvidos um sentimento de corresponsabilidade, com esse vínculo estabelecido é possível alcançar de forma plena os objetivos pretendidos. Por tanto, fica claro que um projeto de mobilização social deve gerar um desenrolar de ações concretas de colaboração, onde os indivíduos se sintam completamente envolvidos no problema que se quer resolver e compartilhem a responsabilidade pela sua solução.

Hoje, com a alta intervenção de uma visibilidade midiática, característica da sociedade contemporânea, é imprescindível que os movimentos de ação social estejam atentos e focados em estabelecer uma comunicação capaz de projetálos no espaço público, não apenas pela sua presença direta, mas com uma presença midiática de forma consistente e marcante.

O grande desafio da comunicação, ao mobilizar, é tocar a emoção das pessoas, sem, contudo, manipulá-las, porque se assim se fizer, ela será autoritária e imposta. Peruzzo [7] observa que estes movimentos implicam o exercício da decisão partilhada e requerem a existência de canais desobstruídos, informações abundantes, autonomia, corresponsabilidade e representatividade.

\section{F. RESPONSABILIDADE SOCIAL}

Para o Instituto Ethos de Empresas e Responsabilidade Social, que é uma Oscip (Organização da Sociedade Civil de Interesse público responsável, responsabilidade social é uma forma de retribuir a alguém e contribuir para uma sociedade digna; é também respeitar o cumprimento dos deveres e obrigações dos indivíduos e empresas para com a sociedade em geral.

A sociedade responde socialmente por suas obrigações que vão além de respeitaras leis, pagar impostos e observar as condições da nossa saúde, e faz isso por acreditar que assim estará contribuindo para um mundo melhor. Diante disso, Paulo Sertek afirma:

A solidariedade ajuda a ver o outro, não como um instrumento qualquer para explorar a pouco custo sua capacidade [...] abandonando-o quando já não serve, mas sim manifesta-se por meio de obras concretas de serviços aos outros [8].

Já é uma exigência cada vez mais presente na sociedade que o ser humano tenha uma conduta que valorize as relações que construídas para que possam gerar valor para todos.

Em um contexto histórico, os primeiros estudos que tratam de Responsabilidade Social iniciaram-se nos Estados Unidos, na década de 50, e posteriormente na Europa, no final da década de 1960. Neste período, o tema foi bastante discutido e buscou-se uma conceituação sobre o termo. Já nas décadas de 1970 e 1980, o conceito de Responsabilidade Social ganhou um amadurecimento, cercado de debates filosóficos no que tange o dever das instituições/organizações na promoção do desenvolvimento social. Nos anos 90, ela passa a incorporar cada vez mais o aspecto normativo e ganhar maior participação de acadêmicos da área da ética dos negócios.

$\mathrm{O}$ autor define Responsabilidade Social ainda como a capacidade de determinada empresa colaborar com a sociedade, considerando valores, normas e expectativas para alcançar seus objetivos [?]. Por tanto o termo Responsabilidade Social pode ser definido pelo conjunto de atitudes e posicionamentos adotados por diversos agentes sociais como empresas, organizações públicas ou privadas, entidades filantrópicas sem fins lucrativos, ou indivíduos sociais que trabalham visando ações voltadas para o desenvolvimento da sociedade.

Considerando que o consumidor está cada dia mais consciente na procura por produtos e práticas que gerem melhoria para o meio ambiente e a comunidade, a responsabilidade social passa a ser usada também como uma estratégia a mais para as empresas para manter ou aumentar sua rentabilidade e potencializar o seu desenvolvimento. Ashely [1] entende o conceito de responsabilidade social da empresa como a responsabilidade de quem deve responder por seus atos mediante a opinião pública, podendo causar consequências sociais na rotina da comunidade. 
Assim, empresas socialmente responsáveis, preocupadas com causas e valores que são refletidos na sociedade, são percebidas pelo público de forma positiva. Estas empresas são entendidas como responsáveis pela implementação de soluções de problemas sociais, e não apenas como instituições preocupadas com lucro e rentabilidade do seu negócio.

Para acompanhar as mudanças que a sociedade vive, as empresas têm assumido posturas diferenciadas em distintos âmbitos do negócio. Uma destas posturas diz respeito à Responsabilidade Social, ou seja, à preocupação com o que a comunidade percebe em sua forma de trabalho e atuação no mercado competitivo.

\section{G. AÇÕES COMUNITÁRIAS - PROJETO EXPERIMENTAL}

A ação comunitária é compreendida como uma atividade dentro da política de responsabilidade social. Em geral, o ser humano possui determinados hábitos que o incentivam a agir e se comportar frente as questões e problemas que o mundo traz.

O trabalho social deve beneficiar principalmente a comunidade, o que acarreta à empresa lucros e benefícios, pois com a implantação da ação poderá atingir um número maior de pessoas favoráveis aquele produto (empresa), o reconhecimento da comunidade e público já existente e a motivação dos funcionários e colaboradores diante dos resultados obtidos.

Para desenvolver um trabalho de cunho comunitário é necessário compreender o conceito de projeto experimental, e tão logo a função de uma ação comunitária direcionada para a população.

Isso posto considera-se que o projeto experimental é uma maneira de fazer a junção prática e teórica em um planejamento que compreenda a abrangência do conhecimento adquirido pelo estudante durante a academia, possibilitando que o acadêmico exercite "suas competências técnicas e criativas aliadas à reflexão teórica.

\section{METODOLOGIA}

Considerando o problema de pesquisa desse estudo, que buscou descobrir "de que forma a disciplina "Ação Comunitária" contribui para a formação de profissionais socialmente responsáveis" a metodologia utilizada foi pesquisa exploratória para a verificação do conteúdo das ações, a abordagem foi quanti-qualitativa e o instrumento de coleta foi entrevistas semiestruturadas.

O Curso de Comunicação Social do Centro Universitário Luterano de Palmas existe desde o ano de 1999. A disciplina de Ação Comunitária está na grade curricular do curso desde 2008. Desde a formação de sua primeira turma até o ano de 2017, cursaram a disciplina 67 alunos do curso de Comunicação Social com habilitação em Jornalismo e 114 alunos do curso de Comunicação Social com habilitação em Publicidade e Propaganda.

Em nove anos a disciplina desenvolveu atividades nas quais os acadêmicos criaram e executaram projetos de Ação Comunitária em eixos de diversas áreas como: saúde, educação, cidadania, filantropia e outros. Os projetos desenvol- vidos foram executados tanto em entidades escolhidas pelo corpo docente do curso como em causas também definidas pelo mesmo corpo.

Até o ano de 2012 os projetos eram ser executados fisicamente em alguma entidade localizada na cidade de Palmas, através de uma lista de ações predefinidas pelos alunos em seu planejamento estratégico de execução. A partir do ano de 2013 os projetos foram transferidos para as plataformas digitais, sendo executados em redes sociais defendendo uma causa específica, escolhida anteriormente pelo corpo docente do curso.

Parte dessa pesquisa foi realizada durante o ano de 2017 e outra parte durante o primeiro semestre de 2018 , onde através de um questionário pudemos enumerar os pontos que seriam fundamentais para termos condições de responder ao nosso problema de pesquisa.

Para que o questionário fosse aplicado em sua integralidade era preciso que os pesquisados preenchessem alguns requisitos que seriam: ser egresso do curso de Comunicação Social do CEULP/ULBRA e ter cursado a disciplina de Ação Comunitária, e estar atuando profissionalmente na área da comunicação.

Estabelecidos estes critérios, passamos a aplicação dos questionários. Foi possível contatar 106 egressos, porém desses a entrevista foi aplicada para 55 egressos que se encaixaram nos requisitos da pesquisa e que se disponibilizaram a responder ao formulário. 55 egressos correspondem a $30 \%$ do universo de 181 alunos que foram formados desde que disciplina foi implantada.

Além da entrevista com os egressos, foram entrevistados a docente responsável em ministrar as aulas da disciplina, a Prof. ${ }^{\text {a }}$ Dr. ${ }^{\text {a }}$ Valdirene Cássia da Silva, a coordenadora do curso de comunicação social do Centro Universitário Luterano de Palmas.

\section{RESULTADOS}

Por meio da aplicação da entrevista semiestruturada foi possível levantar que $100 \%$ dos egressos entrevistados consideram que a disciplina de Ação Comunitária contribui na formação de profissionais da comunicação socialmente responsável. Esse resultado mostra que a disciplina cumpre o objetivo proposto no plano de ensino, e evidencia ainda que os acadêmicos são conscientes da importância dessa disciplina para a formação do sujeito social e do profissional da comunicação consciente do seu papel social dentro das empresas e organizações.

Dentro do universo pesquisado os egressos e agora profissionais da comunicação concordam que a disciplina de Ação Comunitária teve bastante contribuição em suas vidas, tanto na formação profissional como na formação pessoal, tendo ela proporcionado a cada um a possibilidade de que pudessem assumir a postura de profissionais mais humanos, dispostos a ajudar o próximo de diversas maneiras, como aponta Vângela Mattos:

A disciplina de Ação Comunitária agregou um enorme valor social para minha formação. Ela pos- 
sibilitou a aplicação de práticas solidárias no meio comercial, pois, é possível aproximar o público através de ações que prezam pelo bem-estar das pessoas, movimentos, entidades etc. No ramo empresarial essas estratégias possibilitam uma aproximação social, uma unificação de empresa e comunidade, promovendo um incrívele amistoso convívio social, resultando em uma forte corrente de confiança. (Vângela Mattos).

Para os egressos através disciplina eles puderam ainda aplicar em suas ações profissionais alguns conhecimentos adquiridos em sala de aula, lançando um olhar diretamente para a comunidade, trabalhando questões éticas e de cidadania em vários conteúdos gerenciados no dia a dia de suas atividades. Monnalisa Coelho reforça correlacionando a disciplina com as práticas na comunicação:
A disciplina de ação comunitária foi de extrema importância para a minha formação profissional, pois pensar em comunicação é também pensar na comunidade, no bem estar social, nas camadas mais pobres da sociedade. É criar ações que tra- gam contribuição para uma comunidade ou uma causa. Eu por exemplo trabalhei com a doação de medula óssea, é preciso desmistificar essa ideia de que comunicação seja publicidade e propaganda, relações públicas ou jornalismo só tem funções de venda, informação e assessoria. Comunicação é sim pensar na coletividade, no social também. (Monnalisa Coelho)

É perceptível que os acadêmicos assimilaram a essência da disciplina e compreenderam sua relevância na construção de um Profissional de Comunicação Socialmente responsável, ratificando que, conforme afirma Requixa, a ação comunitária tem como objetivo:

[...] despertar e ampliar sua consciência para os problemas da comunidade, sensibilizá-las para a mobilização e coordenação de lideranças e predispô-las para a ação que vise o encaminhamento de soluções daqueles problemas, ou a tentativa de realização de aspirações relacionadas com a comunidade como um todo [16].

Os egressos acrescentam que os desafios oferecidos pela disciplina foram cruciais para o entendimento da comunicação aplicada à realidade institucional, onde planejar e executar um programa de comunicação exige um olhar voltado às necessidades de um cliente e a realidade a sua volta, conforme relatou a egressa Andressa Lunna:

Em primeiro lugar, esta disciplina me deu a real vivência de propagar uma mensagem, uma vez que a essência da nossa profissão é disseminar uma informação. Quero dizer que, em geral, nas outras disciplinas aprendemos a vender algo/alguém, trabalhando instintos mais compulsivos no público, porém, nesta disciplina nos aprofundamos ainda mais no sentido de "vender" a ideia, pois esta de fato o público tem que acreditar para comprá-la. Digamos que é mais fácil vender algo comercial do que fazer alguém se convencer de uma ideologia. Em segundo plano, não menos importante, a experiência do projeto experimental trouxe um lado mais humanitário à profissão. Aprendi sobre a responsabilidade social que o comunicador tem na sociedade. (Andressa Lunna de Jesus)

Pode-se perceber pela análise feita acima que a disciplina cumpre o seu papel na formação de sujeitos sociais mais conscientes em relação ao social e também no objetivo de formar profissionais capazes de aplicar conhecimentos técnicos em ações voltadas para políticas de Responsabilidade social. Quando questionados sobre os aspectos positivos e negativos em trabalhar num planejamento de comunicação, cuja estratégia visa ações sociais e a cidadania, grande parte dos entrevistados consideram como aspecto positivo o fato de poder promover solidariedade e o bem estar da comunidade. De acordo com o egresso, Rodrigo Correia, que atua na área de assessoria de comunicação, os pontos são considerados da seguinte forma:

Em minha experiência, compartilhada com um grupo de colegas do curso de graduação, ao trabalhar com a Associação de Apoio e Recuperação da Família Presidiária (ARAP), tive a oportunidade, muito rara à um aluno de graduação, de lidar com um tema sério e crítico do universo de ações sociais. Como ponto positivo destaco a liberdade e autonomia para gerenciar a relação entre a entidade assistida e nosso projeto de comunicação, que foi conduzido de acordo com os nossos conjuntos de competências e habilidades e, mais que isso, com nossa percepção enquanto futuros profissionais de comunicação. Essa autonomia gera autoconfiança, o que vejo como essencial para a condução da carreira. Em uma contraparte negativa, acredito que a pontualidade das ações desenvolvidas, que, invariavelmente, encontram pouca continuidade ao fim da disciplina não deixa margem para considerarmos a curva de crescimento profissional e acadêmica. $\mathrm{O}$ que quero dizer é que considero que Ação Comunitária não deva ser apenas uma disciplina, mais que isso, um eixo de formação que deveria contemplar mais disciplinas durante a grade de graduação, permitindo continuidade nas ações e solidez na formação para ações sociais. (Rodrigo Correia).

Observa-se na fala do Egresso Rodrigo Correia a grande contribuição da disciplina, pois na opinião dele Ação Comunitária não deveria ser apenas uma disciplina, mas deveria ser um eixo de formação. Quando questionada sobre quais características ela considera fundamental em um profissional de comunicação socialmente responsável, a professora da disciplina Valdirene Cássia responde da seguinte forma:

Ele tem que tomar a comunicação como o espaço 
e uma condição de humanização, então a maior característica é a sensibilidade desse profissional em relação aos problemas que as organizações, de certa forma causam nos agrupamentos sociais. Então a grande característica de um profissional de comunicação socialmente responsável é quando ele percebe o macro e o micro sistema social, e saber que de alguma maneira a comunicação pode fazer uma diferença ali, através de trabalhos, olhares e posições mais humanizadas. Sem dúvida, a principal característica do profissional é estar absolutamente convencido que as estratégias de comunicação devem contemplar ações que promovem comportamentos e discussões que visam práticas voltadas à cidadania. (Valdirene Cássia da Silva)

Valdirene destaca a sensibilidade como principal característica que um profissional de comunicação socialmente responsável deve ter, sensibilidade essa que vai permitir que esse profissional mergulhe nas questões sociais e se sinta, enquanto comunicólogo co-responsável pelas soluções de tais questões, que ele seja capaz de perceber onde a comunicação pode entrar nesse processo, influenciando pessoas de forma positiva sobre determinada causa.

Para o egresso, Allan Monteiro as principais características de um profissional de comunicação socialmente responsável são:

Um profissional imerso nas realidades sociais, neutro, sem levantar bandeiras pelo lado A ou B. Uma comunicação socialmente responsável só é possível por um profissional coerente com a realidade, que tenha o discernimento da importância das ações sociais, que busque através do conhecimento os meios necessários para resoluções dos embates sociais. Um perfil de profissional que tenha a comunicação "pura" como principal ferramenta de suas atividades, mais do que interesses partidários, financeira e tendencial. (Allan Monteiro)

A ideia do egresso Alan Monteiro vem ratificar a fala da professora quando ele afirma que para que seja possível uma comunicação socialmente responsável é imprescindível que ela seja feita por um profissional ciente da importância das ações sociais. Aos egressos foi direcionada a seguinte questão: Você se considera um profissional de comunicação socialmente responsável?

Dos egressos, apenas uma afirmou não poder dizer de forma positiva ser socialmente responsável como profissional da comunicação, uma vez que, tendo projetos que busquem o bem estar da sociedade, tais projetos não saíram do papel. Embora a grande maioria dos egressos tenha respondido que se considera um profissional de comunicação socialmente responsável, foi relatado por eles que não é fácil conseguir aprovação da alta gestão em um projeto que não vise lucro financeiro e que é um trabalho árduo mostrar para chefia que projetos sociais trazem retorno de imagem a médio e longo prazo. Dessa forma conclui-se que o profissional de comunicação, através da disciplina de Ação Comunitária, passa por uma transformação e assume características mais humanizadas para cumprir seu papel de comunicólogo de forma socialmente responsável.

Ao serem questionados sobre a influência da disciplina de Ação Comunitária em sua atuação como profissional de comunicação, 48 dos entrevistados responderam que já aplicam os conhecimentos adquiridos na disciplina de ação comunitária em sua vida profissional. Ou seja quase $49 \%$ do universo pesquisado já executa planejamentos de comunicação voltados para ações comunitárias nas organizações onde atuam. Sobre essa questão a egressa Andressa Lunna afirma:

Atualmente eu aplico diretamente em ações do Programa Qualidade de Vida que existe na instituição que eu trabalho. Como o programa visa o trabalho para melhoria do servidor, não só eu, mas como toda equipe de comunicação procurar transmitir mensagens de cunho social, como: campanhas de conscientização ambiental, campanha de arrecadação à desfavorecidos e campanhas de saúde que envolvem o coletivo (doação de sangue, por exemplo). (Andressa Lunna)

A egressa Andressa atua hoje como analista de comunicação do Instituto Federal do Tocantins, na diretoria de comunicação. Na sua resposta é possível observar que ela exerce os conhecimentos da disciplina na instituição onde atua, ajudando a criar e a implementar projetos voltados para o social.

O Egresso Rodrigo Correia que hoje atua como analista de comunicação de uma multinacional, a BRK Ambiental, quando questionado sobre de que forma aplica os conhecimentos adquiridos na disciplina responde:

Durante 2 anos e meio $(2012$ - 2015) fui repórter e editor de mídia impressa, trabalhando com jornalismo diário. Nesse período, vivi a experiência de colher depoimentos, construir matérias, planejar abordagens e relatar a vida de instituições e pessoas. Percebo que em grande parte, minha desenvoltura neste campo só foi possível a partir do degrau estabelecido em algumas disciplinas, não somente Ação Comunitária, cursadas durante a graduação. Hoje atuo em uma empresa que presta serviços de tratamento de água e coleta e tratamento de esgoto para mais de 1 milhão de habitantes. São mais de mil pessoas que têm como objetivo operar sistemas de saneamento para cidades do Tocantins e do Pará. Aqui estou há dois anos (2015 - 2017) e tenho tido a possibilidade de aplicar minhas competências jornalísticas em projetos diversos. (Rodrigo Correia).

Assim como Rodrigo Correia, a maioria dos egressos relatara em suas repostas os projetos que já executou em suas funções profissionais usando os conhecimentos adquiridos na disciplina de projeto experimental - ação comunitária. Hérica Rocha, por exemplo, atuando com assessoria política, quando 
questionada onde e como aplica esses conhecimentos adquiridos na disciplina enfatiza: "Aplico em todas as ações sociais dos meus clientes, sejam eles, figuras políticas,empresas, figuras públicas ou entidades e instituições privadas". (Hérica Rocha)

Uma minoria respondeu que nem sempre é possível utilizar as experiências vividas durante o estudo da disciplina, porém quando possível eles usam sim estratégias da mesma em suas vidas profissionais.

Letícia Bender atua como Assessora de Comunicação da Instituição de Ensino Superior, Centro Universitário Luterana de Palmas e afirmou em sua entrevista que aplica esses conhecimentos deforma natural, já que essas características já passaram a fazer parte do dia a dia dela enquanto sujeito social:

Acredito que demonstramos a responsabilidade social principalmente nas pequenas ações diárias. Estas alimentam a rotina e demonstram quais são os reais objetivos do negócio. $\mathrm{Na}$ instituição em que atuo, destacar ações de integração, atendimento à comunidade, sensibilidade ao lidar com diferenças culturais/religiosas, acessibilidade faz parte de prioridades de atuação. (Letícia Bender).

A resposta da Letícia vem frisar ainda mais a relevância dos conhecimentos adquiridos nessa disciplina na atuação profissional do comunicólogo que se propôs ser socialmente responsável. Nessa análise pudemos perceber que os egressos do Curso de Comunicação social do CEULP ULBRA aplicam esses conhecimentos de forma natural nas suas atuações profissionais.

Quando questionados se já tinham executado trabalhos de Comunicação com Responsabilidade social na empresa onde trabalham, $75 \%$ responderam que Sim e $25 \%$ responderam que Não. Em seguida perguntamos que tipos de trabalhos de Comunicação com Responsabilidade social já realizaram na vida profissional e os egressos fizeram os seguintes apontamentos:

Desde que ingressei no IFTO, trabalhei com campanhas de final de ano: divulgação e arrecadação de brinquedos para crianças carente, divulgação e arrecadação de alimentos à comunidade baixa renda, divulgação e arrecadação de materiais de higiene para hospital infantil, divulgação e incentivo à presentear com produtos natalinos os funcionários terceirizados da instituição. Também trabalhamos campanhas de: doação de sangue, coleta seletiva, reciclagem de lixo, responsabilidade no consumo de energia e água. (Andressa Lunna).

O IFTO - Instituto Federal do Tocantins, instituição onde Andressa trabalha, é uma Rede Federal de Educação Profissional, Científica e Tecnológica. Andressa faz parte da diretoria de comunicação do Instituto e é outro exemplo de egressa que entendeu a sua função profissional/social, pois atua de forma ostensiva nas ações de Responsabilidade Social da Instituição onde trabalha.
Para os egressos a forma como um profissional socialmente responsável pode influenciar o projeto de uma empresa pode subir em diversos vieses, como em intersecção de áreas com olhares contabilistas, jurídicos, operacionais, estratégicos e outros que podem ser considerados como espaços para a atuação de um profissional que, antes de tudo, buscará analisar as demandas através da preocupação com a responsabilidade social.

O egresso Rodrigo Correia apresenta um exemplo a respeito dos espaços de atuação: Trabalho em uma empresa de saneamento e como profissional de comunicação fui sempre orientado a aprender a comunicar sobre novas obras de ampliação de nossa rede de abastecimento de água através do viés "números de pessoas beneficiadas" e não "quilometragem de rede ampliada". A linguagem, matéria prima da função de comunicador, já moldada a colocar as pessoas no início, no meio e no fim dos projetos.(Rodrigo Correia).

Atuando em levantar causas coletivas, o profissional de Comunicação Social, consciente do seu papel social pode influenciar de forma muito positiva os projetos das empresas onde atuam. Fica evidente pelas respostas dos egressos que a disciplina Ação Comunitária trabalha com a concepção de desenvolvimento humano, integral, permanente, universal e solidário. Para elucidar ainda mais esses apontamentos recorremos a mais uma citação da UNESCO sobre o papel social da Universidade: "[...] poderoso meio de transformações comprometidas com a superação do conjunto da sociedade, com a preservação e desenvolvimento de todos os coletivos humanos e suas culturas e com a globalização da solidariedade e da paz" [11].

A Professora da disciplina em sua entrevista, quando questionada sobre de que forma ela considera que a disciplina Ação Comunitária contribui para o cumprimento também do papel social da Universidade, diz que:

A Universidade tem um grande papel social, ela precisa desempenhar uma política de responsabilidade social. Sou ciente de que somente implementar uma disciplina não garante a ela ser uma instituição que cumpre com seu papel social, eu tenho consciência disso, mas quando a instituição insere essa cadeira ela já demonstra pelo menos um traço de consciência de que a instituição tem esse compromisso. E a Instituição de Ensino superior tem uma obrigação, enquanto formadora de sujeitos sociais, que vão desempenhar papeis importantíssimos também com agrupamentos sociais, ela tem uma obrigação gigante de formar seus profissionais a luz dessa consciência, a luz dessas posições e dessa filosofia, enfim dessa política que é a da Responsabilidade social, e a partir dessa política formar sujeitos consigam contribuir com ações sociais e comunitárias. (Valdirene Cássia da Silva). 
Os egressos acrescentam que todo o conhecimento adquirido por eles durante o estudo da disciplina de Ação Comunitária, de uma forma ou de outra, em grande ou menor escala foram absorvidos pelos colaboradores e colegas de trabalho, sendo que cada um deles, em algum momento consegue orientar os colegas a seguirem o melhor caminho para o exercício dos interesses institucionais, que se resume na cidadania e responsabilidade social.

\section{CONSIDERAÇÕES FINAIS}

O objetivo central dessa pesquisa consistiu em analisar se disciplina de Ação Comunitária do curso de Comunicação Social do CEULP ULBRA contribui na formação de sujeitos socialmente responsáveis. Para tanto buscou-se dar voz aos egressos que passaram por essa disciplina durante sua formação acadêmica no curso de Comunicação Social da instituição já citada, assim também como a professora da disciplina para melhor compreender a dinâmica do Projeto Experimental de Ação Comunitária.

Através de uma entrevista semiestruturada foi possível identificar que os egressos se consideram profissionais da comunicação socialmente responsáveis e consideram a importância da disciplina nessa construção. Na trajetória da investigação observou-se que os profissionais entrevistados exercem de forma ética e consciente o seu ofício na Comunicação das Instituições Palmenses, se preocupam em aliar técnica com Responsabilidade Social e fazem questão de inserir projetos sociais nos planejamentos realizados nas instituições onde trabalham.

Com base nos apontamentos feitos em cada uma das categorias levantadas no processo de investigação da pesquisa, pudemos sim validar a hipótese de que a disciplina influenciou de forma positiva a vida profissional dos egressos, imprimindo neles a importância de serem agentes na comunicação socialmente responsáveis ao ponto de buscarem meios de inserir em seus trabalhos como profissionais, projetos com cunho social que enaltecem não apenas as estratégias de comunicação, mas que proporcionam as empresas que eles representam levar as comunidades onde atuam a imagem de que são instituições socialmente responsáveis e comprometidas com melhorias para a sociedade de forma humana e cidadã.

E nessa trajetória, usando criativamente a tarefa de pesquisador, defendemos a imensa necessidade de se trabalhar responsabilidade social nos cursos de Comunicação Social, pois os resultados dessa pesquisa apontam para uma percepção ética aguçada por parte dos egressos, aliada a um desejo de participação ainda maior com projetos sociais.

Há que se reconhecer que a Universidade tem o papel de promover oportunidades de participação e engajamento em programas de responsabilidade social junto à comunidade em torno dela, e isso é possível quando se trabalham projetos experimentais de Ação Comunitária.

\section{Referências}

[1] ASHELY P.A. (2002). Ética e Responsabilidade Social nos Negócios. São Paulo. Saraiva.

[2] ARAÚJO, I. S.; CARDOSO, J. M. (2007) Comunicação e Saúde. Rio de Janeiro: FIOCRUZ, p.152.

[3] BUARQUE, C. (1994) A Aventura da Universidade. São Paulo: Editora da Universidade do Estado de São Paulo. P. 239.

[4] CHARLOT, B. (2000). Da relação com o saber: elementos para uma teoria. Porto Alegre: Artemed.

[5] HENRIQUES, M. S. (Org.). Comunicação e estratégias de mobilização social. Belo Horizonte: Autêntica.

[6] MELO, P. A. de e NOVO, L. F. Artigo: Universidade Empreendedora: fortalecendo os caminhos para a responsabilidade social. Apresentado no III Colóquio.

[7] PERUZZO, C. M. K. (2002) Comunicação Comunitária e Educação para a Cidadania. São Paulo: PCLA - Volume 4 - número 1: outubro / novembro /dezembro.

[8] SERTEK, P. (2006) Responsabilidade social e competência interpessoal. 1. ed.- Curitiba: Ibpex.

[9] TORO, J. B.; WERNECK, N. M. D. (1996) Mobilização social: um modo de construir a democracia e a participação. Brasília: Ministério do Meio Ambiente, Recursos Hídricos e Amazônia Legal, 1996. 104 p.

[10] UNESCO. Declaração Mundial sobre educação superior no século XXI São Gonçalo: UNIVERSO, 1999.

[11] OLIVEIRA, J. A. (1984). Responsabilidade social em pequenas e médias empresas. Revista de Administração de Empresas, 24(4), 203-210

[12] Freire, P. (1967). Educação como prática da liberdade [Education as the Practice of Freedom]. Rio de Janeiro: Paz e Terra.

[13] REQUIXA, R. (1973). Lazer e ação comunitária. São Paulo: SESC.

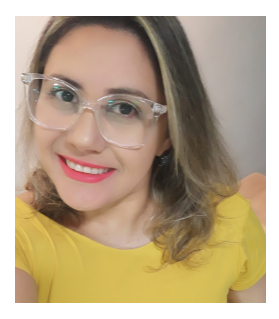

SUZI AMÉRICO NOGUEIRA DA SILVA

Graduada em Comunicação Social com habilitação em Publicidade e Propaganda (CEULP/ULBRA), Pós graduada em "Comunicação, Educação e Novas Tecnologias"(UNITINS), Mestre em Comunicação Estratégica - Publicidade e Relações Públicas pela Universidade da Beira Interior - (UBIPortugal) e Doutoranda em Ciência Comunicação pela Universidade da Beira Interior em Portugal. (UBI - Portugal)

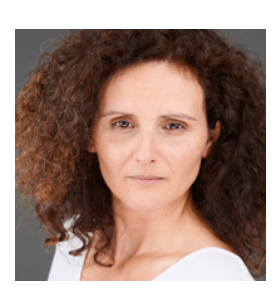

ANA LEONOR MORAIS SANTOS

Licenciada em Filosofia pela Universidade Católica Portuguesa (Lisboa). Mestre em Filosofia pela Universidade da Beira Interior, com tese em Ética distinguida com o prêmio D. Dinis. Doutora em Filosofia pela UBI. Vice-presidente do Comitê de Ética da UBI. 